\title{
Carriage of class 1 integrons and antibiotic resistance in clinical isolates of Acinetobacter baumannii from Northern Spain
}

\author{
LUCIA GALLEGO and KEVIN J. TOWNER*
}

Departamento de Immunologia, Microbiologia y Parasitologia, Facultad de Medicina y Odontologia, Universidad del Pais Vasco, 48080 Bilbao, Spain and *Department of Microbiology \& PHLS Laboratory, University Hospital, Queen's Medical Centre, Nottingham NG7 2UH

\begin{abstract}
A collection of 70 clinical isolates of Acinetobacter baumannii from Bilbao in northern Spain was examined by PCR for the presence of class 1 integron structures. The organisms comprised 21 distinct RAPD genotypes, with 10 distinct antibiogram patterns. Four different integron structures were detected in a total of $59(84 \%)$ of the 70 isolates, with two predominant integron structures found in 20 and 30 isolates each. No clear antibiogram differences could be correlated with the presence or absence of integron structures, but sequence analysis of two of the internal integron regions indicated homology with genes encoding ANT(2") adenyltransferase activity and AAC(6')-Ib acetyltransferase activity. Phenotypic analysis of aminoglycoside resistance profiles indicated that many isolates produced a combination of aminoglycoside-modifying enzymes, with most of the observed resistance to amikacin being associated with a gene encoding APH(3')-VI phosphotransferase, as detected by PCR. RAPD analysis indicated that all the Bilbao isolates producing $A P H\left(3^{\prime}\right)-V I$ were distinct from an epidemic integron-carrying and APH(3')-VI-producing Acinetobacter strain found in other regions of Spain. It is concluded that, although class 1 integrons are widely disseminated amongst clinical isolates of $A$. baumannii from the Bilbao region of Spain, at present they are not playing a major role in the dissemination of antibiotic resistance genes in this region.
\end{abstract}

\section{Introduction}

Members of the genus Acinetobacter, predominantly $A$. baumannii, are recognised as increasingly important nosocomial pathogens, especially in intensive care units, where they are associated particularly with nosocomial pneumonia [1]. Such infections are often difficult to treat because of the ability of acinetobacters to become rapidly resistant to multiple antibiotics, including aminoglycosides, expanded-spectrum cephalosporins, carbapenems and fluoroquinolones [1,2]. Some strains are effectively untreatable, and the severity and difficulties associated with nosocomial infection by $A$. baumannii are related directly to the particularly high rates of resistance found [3].

Received 31 Jan. 2000; revised version accepted 10 May 2000.

Corresponding author: Dr K.J. Towner (email: Kevin.Towner @ nottingham.ac.uk).
As in other species, plasmids and transposons play an important role in the acquisition of antibiotic resistance by Acinetobacter spp. [4]. In addition, antibiotic resistance in Acinetobacter spp., particularly to aminoglycosides, has been associated increasingly with the presence of integrons [5-8]. These elements possess a site-specific recombination system enabling the insertion, deletion and re-arrangement of discrete genetic cassettes, often comprising antibiotic resistance genes, within the integron structure [9-13]. Several classes of integrons have been described [13], with class 1 integrons being the most common and widely distributed among gram-negative bacteria $[14,15]$. Integrons have been found in isolates of Acinetobacter spp. from various locations worldwide $[5,7,8]$ and it has been suggested that multiresistant isolates of Acinetobacter spp. may act as a reservoir of integronassociated antibiotic resistance genes, which could then spread to other pathogens in the hospital environment [8].

The main aim of the present study was to determine 
the prevalence of class 1 integrons among nosocomial isolates of $A$. baumannii from the city of Bilbao in northern Spain, and to examine whether there was any correlation between antibiotic resistance and carriage of class 1 integrons. The Hospital of Santa Marina, Bilbao, is a 200-bed institution specialising in respiratory illness. Infections caused by $A$. baumannii are a particular problem. An epidemic strain of $A$. baumannii carrying a class 1 integron has been reported previously in Barcelona and other regions of Spain $[6,8,16]$ and the study also aimed to establish whether this strain had spread from Barcelona to Bilbao.

\section{Materials and methods}

\section{Bacterial strains}

In total, 70 isolates of $A$. baumannii were obtained from different patients attending the Hospital of Santa Marina, Bilbao, Spain, from June 1998 until April 1999. The specimens from which A. baumannii were isolated comprised 58 sputum samples, three blood cultures, one broncho-alveolar sample, one urine, three wound swabs, three pleural aspirates and one stool. All the isolates were identified initially with the API 32 system (bioMérieux, Marcy l'Etoile, France), with identification to the level of genomic species being confirmed by tDNA fingerprinting [17]. The isolates were stored at $-20^{\circ} \mathrm{C}$ in nutrient broth containing glycerol $50 \% \mathrm{v} / \mathrm{v}$ before inclusion in this study. An integron-carrying strain of $A$. baumannii from Barcelona (generously donated by Professor J. Vila), designated previously as strain Ab41 [6] or strain ESP41 [8], was included in the study, as was the sensitive type strain of A. baumannii, ATCC 19606.

\section{Antibiotic profiles}

MICs for the isolates were determined by the broth micro-dilution method described by the National Committee for Clinical Laboratory Standards [18], with Pseudomonas aeruginosa strain ATCC 27853 as a control. The antibiotics tested were aztreonam, cefepime, cefotaxime, ceftazidime, imipenem, meropenem, ticarcillin, amikacin, gentamicin, ciprofloxacin, levofloxacin, norfloxacin and ofloxacin. Similarity coefficients $\left(\mathrm{S}_{\mathrm{AB}}\right.$ values) were calculated and subjected to cluster analysis as described previously [19], except that MIC values rather than inhibition zone sizes were used. Aminoglycoside resistance profiles were analysed further by a disk method, with 12 different drug analogues [20].

\section{DNA fingerprinting}

Total genomic DNA extracts of $A$. baumannii isolates were prepared [21] and then compared by analysis of randomly amplified polymorphic DNA (RAPD) fingerprints, obtained with primers AP3 [22] and ERIC2 [21]. Previous investigations have determined that good discrimination between genetically unrelated groups of Acinetobacter spp. is achieved at an $\mathrm{S}_{\mathrm{AB}}$ value of 0.7 [21]; therefore, isolates that clustered together with an $\mathrm{S}_{\mathrm{AB}}$ value of $>0.7$, with both primers, were considered to be closely related and to form a single RAPD genotype. Comparison of isolates from Bilbao and Barcelona was performed with M13 core primer, as described previously [21].

\section{Detection and characterisation of class 1 integrons}

Total genomic DNA extracts of $A$. baumannii isolates were used as templates in PCR experiments to detect the hot-spot insertion regions of class 1 integrons. Each PCR was performed with a Ready-To-Go PCR bead (Amersham Pharmacia Biotech, Little Chalfont, Bucks) in a final $25-\mu \mathrm{l}$ volume containing $5 \mu \mathrm{l}$ of DNA extract and $2.5 \mathrm{pmol}$ each of primers $5^{\prime} \mathrm{CS}$ and $3^{\prime} \mathrm{CS}$, as described previously [8]. Initial comparison of the inserted cassettes in the class 1 integron structures detected was performed by taking 5 - $\mu 1$ portions of the primary PCR products and digesting them with HinfI, as described previously [8].

Further PCR analysis of possible inserted cassettes was performed by taking total genomic DNA or initial integron PCR products and using the primers and methodology described by Vila et al. [16] to seek the aph $\left(3^{\prime}\right)$-VIa gene, which is reported to be responsible for much of the amikacin resistance found in $A$. baumannii isolates from Spain [16].

\section{Preliminary sequence data}

Cycle sequencing of PCR products, purified with a GFX PCR DNA Gel Band Purification Kit (Amersham), was performed with the 5'CS primer and a Cy5 Thermo Sequenase Dye Terminator Kit (Amersham), with both kits used as recommended by the manufacturer. DNA sequencing reactions were analysed on acrylamide (Premix Long Ranger Gel Solution; Flowgen, Ashby de la Zouch, Leics) $6 \% \mathrm{w} / \mathrm{v}$ gels in an automated ALFexpress DNA Sequencer (Amersham). The DNA sequences obtained were screened against known sequences contained in nucleic acid sequence databases by the BLAST (Basic Local Alignment Search Tool) on-line method (www.ncbi.nlm.nih.gov/ BLAST/).

\section{Results}

\section{DNA fingerprinting experiments and antibiograms}

Twenty-one distinct RAPD genotypes of A. baumannii were identified among the 70 isolates included in the study; these are listed in Table 1, together with antibiogram data for one isolate of each type. Three genotypes (P, Q and R; Table 1) predominated, collectively accounting for $44(63 \%)$ of the 70 isolates. 
Table 1. Antibiograms for A. baumannii isolates representing the 21 RAPD genotypes delineated during the study

\begin{tabular}{|c|c|c|c|c|c|c|c|c|c|c|c|c|c|c|c|}
\hline \multirow{2}{*}{$\begin{array}{l}\text { RAPD genotype } \\
\text { (number of isolates) }\end{array}$} & \multirow{2}{*}{$\begin{array}{l}\text { Representative } \\
\text { isolate }\end{array}$} & \multirow[b]{2}{*}{ Origin } & \multicolumn{13}{|c|}{ MIC $(\mathrm{mg} / \mathrm{L})$} \\
\hline & & & TIC & CTX & CAZ & CFM & IMP & MEM & $\mathrm{AZT}$ & AMI & GEN & NOR & CIP & LEV & OFL \\
\hline A (2) & SM10 & $\mathrm{Spt}$ & 128 & 128 & 128 & 128 & $>128$ & $>128$ & 128 & 32 & $>128$ & $>128$ & 64 & 16 & 64 \\
\hline B (1) & SM12 & Spt & $>128$ & 16 & $>128$ & 128 & $>128$ & $>128$ & 32 & 4 & $>128$ & $>128$ & 32 & 16 & 16 \\
\hline C (2) & SM13 & $\mathrm{B} / \mathrm{c}$ & 32 & 1 & $>128$ & 64 & 32 & 8 & 32 & 4 & $>128$ & $>128$ & 32 & 16 & 16 \\
\hline D (1) & SM15 & Spt & 1 & 1 & 1 & 32 & 8 & 2 & 4 & 4 & $>128$ & 64 & 8 & 8 & 8 \\
\hline E (1) & SM16 & Spt & 128 & 64 & $>128$ & 128 & $>128$ & $>128$ & 32 & 32 & $>128$ & $>128$ & 64 & 16 & 32 \\
\hline F (1) & SM17 & Spt & 4 & 1 & 1 & 64 & 2 & 2 & 8 & 2 & $>128$ & 1 & $<1$ & 2 & 2 \\
\hline G (1) & SM18 & Spt & 1 & $<1$ & $<1$ & 32 & $<1$ & $<1$ & $<1$ & 4 & $>128$ & 64 & 8 & 8 & 8 \\
\hline H (4) & SM20 & Wnd & 1 & $<1$ & $<1$ & 64 & $<1$ & $<1$ & $<1$ & 1 & $>128$ & 64 & 16 & 16 & 16 \\
\hline I (1) & SM21 & Spt & 32 & 4 & $<1$ & 4 & 4 & 16 & 4 & 4 & 4 & 2 & 2 & 4 & 4 \\
\hline $\mathrm{J}(2)$ & SM25 & Spt & 16 & 64 & $<1$ & 1 & 8 & 2 & 1 & 1 & 1 & 2 & $<1$ & 2 & 2 \\
\hline K (1) & SM27 & Spt & 32 & 64 & 16 & 16 & $<1$ & 2 & 32 & 8 & $>128$ & $>128$ & 128 & 32 & 32 \\
\hline L (1) & SM28 & Spt & $>128$ & $>128$ & $>128$ & $>128$ & $>128$ & $>128$ & 128 & 32 & $>128$ & $>128$ & 128 & 32 & 32 \\
\hline M (3) & SM29 & Spt & $>128$ & $>128$ & $>128$ & 64 & $>128$ & $>128$ & 128 & 64 & $>128$ & $>128$ & 128 & 16 & 32 \\
\hline N (1) & SM30 & Plp & $>128$ & $>128$ & $>128$ & 64 & $>128$ & $>128$ & 128 & 32 & $>128$ & $>128$ & $>128$ & 16 & 32 \\
\hline O (1) & SM33 & Spt & 8 & 16 & 8 & 16 & $<1$ & $<1$ & 16 & 8 & $>128$ & $>128$ & 64 & 16 & 32 \\
\hline P (14) & SM36 & Spt & $>128$ & $>128$ & $>128$ & 32 & $>128$ & $>128$ & 128 & 128 & $>128$ & $>128$ & 128 & 16 & 32 \\
\hline Q (23) & SM80 & Spt & $>128$ & $>128$ & 64 & $>128$ & $>128$ & 128 & 128 & 64 & $>128$ & $>128$ & 128 & 16 & 32 \\
\hline $\mathrm{R}(7)$ & SM49 & Spt & 128 & 64 & 128 & 128 & 32 & 16 & 32 & 32 & $>128$ & 64 & 64 & 16 & 32 \\
\hline S (1) & SM52 & Spt & 16 & 4 & 4 & 8 & 4 & 16 & 16 & 32 & 2 & 4 & 4 & 16 & 16 \\
\hline T (1) & SM69 & Spt & $>128$ & $>128$ & 16 & 16 & 64 & 32 & 32 & 32 & 64 & $>128$ & 64 & 16 & 32 \\
\hline U (1) & SM77 & Spt & 64 & 128 & 32 & 32 & 4 & 1 & 64 & 32 & 64 & 128 & 32 & 8 & 16 \\
\hline
\end{tabular}

Spt, sputum; B/c, blood culture; Wnd, wound; Plp, pleural aspirate; TIC, ticarcillin; CTX, cefotaxime; CAZ, ceftazidime; CFM, cefepime; IMP, imipenem; MEM, meropenem; AZT, aztreonam; AMI, amikacin; GEN, gentamicin; NOR, norfloxacin; CIP, ciprofloxacin; LEV, levofloxacin; OFL, ofloxacin. 
Minor variations in antibiograms were observed within each genotype, and the isolates listed are the most resistant representatives of each type. Antibiograms with an $\mathrm{S}_{\mathrm{AB}}$ value of $>0.9$ were considered to be indistinguishable. On this basis, 10 distinct antibiograms were distinguishable among the 21 different genotypes, of which the most common was shared by $54(77 \%)$ isolates belonging to 10 genotypes (A, B, E, L, M, N, P, Q, R and T). None of the other antibiograms was shared by more than two genotypes.

\section{Detection of class 1 integrons by PCR}

Amplification with primers specific for the $5^{\prime}$ and $3^{\prime}$ conserved regions of class 1 integrons yielded PCR products from 59 of the 70 isolates. Four predominant PCR products of 760, 550, 800 and $600 \mathrm{bp}$ were visualised (Table 2). Additional faint PCR products of various sizes were visualised occasionally, but were not reproducible and were not investigated further. Four different HinfI fingerprint patterns, corresponding to the four predominant PCR products, were obtained and designated $a-d$ (Table 2). The most common structures were $a$ and $b$, found in 20 and 30 isolates, respectively. Structures $c$ and $d$ were detected in eight isolates and one isolate, respectively. Based on the sizes of the inserted cassette regions detected and the reported sizes of previously characterised gene cassettes [23], it seemed likely that each of the four integron structures contained one, or at most two, inserted gene cassettes. Integrons of the same internal structure were found in more than one Acinetobacter genotype, but no single genotype contained more than one type of integron structure (Table 2).

\section{Correlation of antibiotic resistance profiles with integron carriage and genotypes}

Attempts were made to correlate the observed minor variations in antibiograms within each genotype with the presence or absence of integron structures, but no clear distinctions could be made. For example, only 10 of the 14 isolates that belonged to genotype $\mathrm{P}$ yielded a type $a$ integron structure, and these 10 isolates varied slightly in antibiotic susceptibilities among themselves and from the four isolates that lacked an integron structure.
For screening purposes, preliminary DNA sequences were generated from the $5^{\prime}$ end of purified PCR products corresponding to the inserted cassette regions in each of the four integron structures. Isolate SM36 (structure $a$ ) yielded a 550-base sequence that showed $95 \%$ base homology with the $a a d B$ gene cassette encoding $\mathrm{ANT}\left(2^{\prime \prime}\right)$ adenyltransferase activity (accession no. U14415 [24]). Similarly, isolate SM49 (structure $c$ ) yielded a 650-base sequence that showed $93 \%$ base homology with an aacA4 gene encoding AAC $\left(6^{\prime}\right)-\mathrm{Ib}$ acetyltransferase activity (accession no. AF043381). Taken together with the amplified external non-coding regions, the known sizes of these $a a d B$ and $a a c A 4$ gene cassettes (591 bp and $637 \mathrm{bp}$, respectively [23]) were sufficient to account for the entire amplified regions (Table 2) of integron structures $a$ and $c$. No significant database homology was detected with a 400-base sequence generated from isolate SM80 (structure $b$ ) or a 650-base sequence generated from isolate SM52 (structure $d$ ).

\section{Phenotypic and genotypic analysis of aminoglycoside resistance genes}

Members of the genus Acinetobacter frequently have complex combinations of aminoglycoside resistance mechanisms [20,25]. Of the two gene cassettes identified here, $a a d B$, encoding $\operatorname{ANT}\left(2^{\prime \prime}\right)$, confers resistance to gentamicin and tobramycin, whereas aacA4, encoding one of the AAC $\left(6^{\prime}\right)$-I family of enzymes, confers resistance to tobramycin, amikacin and netilmicin. Amikacin resistance in Acinetobacter spp. can be associated with production of either $6^{\prime}-N-$ acetyltransferase type I (AAC(6')-I) enzymes [26] or $3^{\prime}$-O-phosphotransferase type VI (APH(3')-VI) [27]. To distinguish these possibilities, total DNA and integron PCR products from the representative isolates listed in Table 1, corresponding to the 21 different genotypes, were screened by PCR for the presence of the $\operatorname{aph}\left(3^{\prime}\right)$ $V I a$ gene. Of the 10 isolates that expressed resistance $(\mathrm{MIC}>16 \mathrm{mg} / \mathrm{L})$ to amikacin, eight (SM10, 16, 28, 29, 30, 36, 49 and 80) yielded a 234-bp PCR product characteristic of the aph(3')-VIa gene [16] when total, but not integron, DNA was used as a template. Thus, the $\operatorname{aph}\left(3^{\prime}\right)-V I a$ gene was widely distributed amongst the different genotypes, but did not form part of the integron structures identified. Isolate SM49 possessed both an $\operatorname{aph}\left(3^{\prime}\right)-V I a$ gene and an integron-associated

Table 2. Characteristics of the inserted cassette regions of the class 1 integron structures detected

\begin{tabular}{llcl}
\hline Integon & $\begin{array}{l}\text { Size } \\
(\mathrm{bp})\end{array}$ & $\begin{array}{c}\text { Hinfl digestion } \\
\text { products }\end{array}$ & $\begin{array}{l}\text { Genotype } \\
\text { (Number of isolates) }\end{array}$ \\
\hline$a$ & 760 & $350,220,190$ & $\mathrm{~A} \mathrm{(1),} \mathrm{C} \mathrm{(2),} \mathrm{F} \mathrm{(1),} \mathrm{H} \mathrm{(2),} \mathrm{I} \mathrm{(1),}$ \\
& & & $\mathrm{K}(1), \mathrm{N}(1), \mathrm{O}(1), \mathrm{P}(10)$ \\
$b$ & 550 & 550 & $\mathrm{~B}(1), \mathrm{L}(1), \mathrm{M}(3), \mathrm{Q}(23), \mathrm{T}(1)$, \\
$c$ & 800 & 550,170 & $\mathrm{D}(1), \mathrm{R}(7)$ \\
$d$ & 600 & $300,170,110$ & $\mathrm{~S}(1)$ \\
\hline
\end{tabular}


aacA4 gene. Two isolates (SM69 and 77) were resistant to amikacin, but lacked an $\operatorname{aph}\left(3^{\prime}\right)$-VIa gene; these isolates were assumed to express an AAC $\left(6^{\prime}\right)-\mathrm{I}$ enzyme, but lacked the type $c$ integron structure found in SM49. In contrast, isolate SM15 contained the type $c$ integron structure, but was susceptible to amikacin (Tables 1 and 2).

Table 3 lists the inhibition zone sizes of aminoglycoside disks for four representative isolates carrying the four different integron structures. Isolate SM52 (integron structure $d$ ) did not differ significantly in behaviour from the sensitive type strain of $A$. baumannii. Therefore, it was concluded that the type $d$ integron structure did not encode aminoglycoside resistance. After taking account of the resistance phenotype associated with aph $\left(3^{\prime}\right)$-VIa (already demonstrated by PCR in isolates SM36, SM49 and SM80), the profiles obtained also suggested production of ANT(2") and an AAC(3) enzyme by isolate SM36, the production of AAC(3)-II by isolate SM80, and the production of $\mathrm{AAC}\left(6^{\prime}\right)$-I and $\mathrm{AAC}(3)$-II by isolate SM49. These results were consistent with the preliminary integron sequencing data in the two cases (isolates SM36 and SM49) where significant homology was identified.

\section{Dissemination of the aph(3')-VI gene in Spain}

Amikacin resistance in Acinetobacter spp. from different regions of Spain has previously been associated with the spread of an epidemic strain carrying the $\operatorname{aph}\left(3^{\prime}\right)-V I$ gene [16]. To determine whether the amikacin resistance found in Bilbao was associated, at least in part, with spread of the same epidemic strain, representatives (SM10, 16, 28, 29, 30, 36, 49 and 80 ) of the eight genotypes found to carry the aph(3')-VIa gene were directly compared in RAPD experiments with the epidemic strain ESP41 found in Barcelona and other regions of Spain. The RAPD profiles obtained with M13 core primer (Fig. 1) indicated that isolates SM28 and SM29 were indistinguishable from each other with this primer (although they were distinguished with primers AP3 and ERIC2), but all eight Bilbao genotypes with the aph(3')-VIa gene were clearly distinguishable from strain ESP41.

\section{Discussion}

Class 1 integron structures were detected by PCR in 59 (84\%) of 70 clinical isolates of $A$. baumannii from Bilbao. Although these clinical isolates were genetically diverse, with 21 distinct genotypes identified, only four integron structures - recognised on the basis of their HinfI restriction endonuclease fingerprint profiles were identified. These structures were disseminated amongst 18 genotypes, with types $a$ and $b$ being found in 20 and 30 isolates, respectively. These findings clearly indicate the spread of integron structures among different A. baumannii genotypes found in Bilbao. However, and in contrast to many integrons found in $A$. baumannii elsewhere in the world [8], the Bilbao structures seemed to have acquired only one (or at most two) inserted resistance gene cassettes.

Ten different antibiograms were seen amongst the 21 genotypes, but there were no clear phenotypic differences between isolates of the same genotype with and without an integron. Preliminary sequence analysis indicated the presence of cassettes encoding ANT( $\left.2^{\prime \prime}\right)$ adenyltransferase and $\mathrm{AAC}\left(6^{\prime}\right)$-Ib acetyltransferase activity for two of the integron structures ( $a$ and $c$, respectively). Aminoglycoside resistance determinants are the predominant gene cassettes found in integrons from gram-negative bacteria [10], including Acinetobacter isolates collected worldwide [8]. However, many multiply-resistant acinetobacters produce complex combinations of aminoglycoside-modifying enzymes, many of which are not encoded by integrons [20,25], and analysis of disk inhibition tests indicated that this was the case for the present isolates.

As a strain of $A$. baumannii carrying a class 1 integron was reported to be widely disseminated in Barcelona and other regions of Spain $[6,8,16]$, it was interesting to determine whether this strain had spread to the Bilbao region. The Barcelona strain encodes $\mathrm{APH}\left(3^{\prime}\right)$ VI, a $3^{\prime}$-O-phosphotransferase that inactivates amikacin

Table 3. Aminoglycoside disk zone sizes and deduced aminoglycoside-modifying enzymes for representative isolates of $A$. baumannii carrying the four integron structures

\begin{tabular}{|c|c|c|c|c|c|c|c|c|c|c|c|c|c|}
\hline \multirow{2}{*}{$\begin{array}{l}\text { Isolate } \\
\text { (integron structure) }\end{array}$} & \multicolumn{12}{|c|}{ Aminoglycoside disk zone sizes (mm) } & \multirow{2}{*}{$\begin{array}{l}\text { Inferred aminoglycoside } \\
\text {-modifying enzymes }\end{array}$} \\
\hline & GEN & TOB & AMK & KAN & APR & NET & $6^{\prime} \mathrm{NET}$ & $2^{\prime} \mathrm{NET}$ & EPI & ISP & FOR & NEO & \\
\hline SM36 (a) & NZ & $\mathrm{NZ}$ & 9 & $\mathrm{NZ}$ & 29 & 19 & 12 & 9 & 21 & $\mathrm{NZ}$ & 24 & 12 & $\begin{array}{l}\operatorname{APH}\left(3^{\prime}\right)-\mathrm{VI}^{*}, \\
\text { ANT(2"), AAC(3)-? }\end{array}$ \\
\hline SM80 (b) & NZ & 16 & 14 & $\mathrm{NZ}$ & 24 & 11 & $\mathrm{NZ}$ & NZ & 19 & 11 & 22 & 13 & $\mathrm{APH}\left(3^{\prime}\right)-\mathrm{VI}^{*}, \mathrm{AAC}(3)-\mathrm{II}$ \\
\hline SM49 (c) & NZ & $\mathrm{NZ}$ & 16 & $\mathrm{NZ}$ & 25 & $\mathrm{NZ}$ & 16 & $\mathrm{NZ}$ & $\mathrm{NZ}$ & 13 & 24 & 11 & $\begin{array}{l}\mathrm{APH}\left(3^{\prime}\right)-\mathrm{VI}^{*}, \\
\mathrm{AAC}(3)-\mathrm{AAC}\left(6^{\prime}\right)-\mathrm{I},\end{array}$ \\
\hline SM52 (d) & 13 & 13 & 24 & 14 & 26 & 25 & 22 & 22 & 23 & 24 & 29 & 23 & None \\
\hline ATCC $19606^{\dagger}$ & 17 & 16 & 25 & $\mathrm{NZ}$ & $\mathrm{NZ}$ & 29 & 20 & 18 & 21 & 23 & 21 & 23 & None \\
\hline
\end{tabular}

AMK, amikacin; APR, apramycin; EPI, episisomicin; FOR, fortimicin; GEN, gentamicin; ISP, isepamicin; KAN, kanamycin; NEO, neomycin; NET, netilmicin; 6'-NET, 6'-netilmicin; 2'Net, 2'-netilmicin; TOB, tobramycin; NZ, no zone.

${ }^{*}$ The presence of the gene encoding APH(3')-VI was confirmed by PCR. ${ }^{\dagger}$ Sensitive type strain of A. baumannii. 


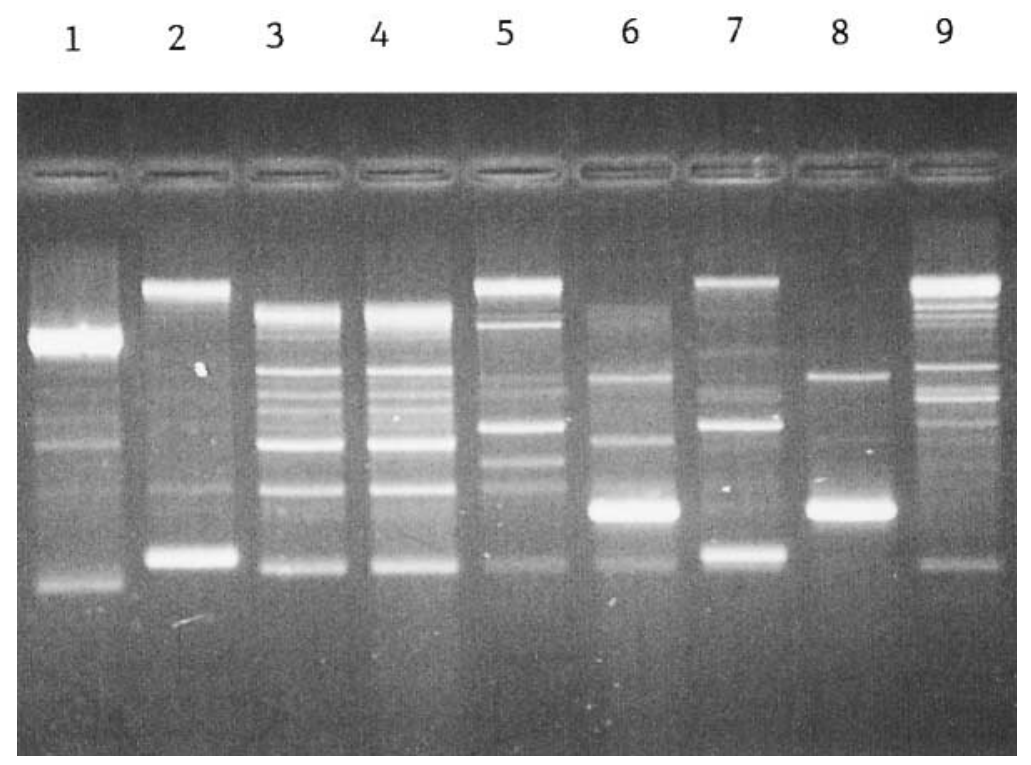

Fig. 1. Comparative RAPD profiles obtained with M13 primer for $A$. baumannii isolates carrying the aph $\left(3^{\prime}\right)-V I$ gene. Lanes: 1, isolate SM10; 2, SM16; 3, SM28; 4, SM29; 5, SM30; 6, SM36; 7, SM49; 8, SM80; 9, ESP41 (epidemic isolate from Barcelona).

[27]. This gene was detected by PCR in eight of the 10 genotypes found in Bilbao that expressed resistance to amikacin. However, all these genotypes were clearly distinguished from the Barcelona strain. As in France [28], it seems that aph $\left(3^{\prime}\right)-V I a$ has spread to several different genotypes, including two predominant types in Bilbao, and that spread of a single resistant strain is not implicated, as in other areas in Spain [16]. Work in France suggests that aph $\left(3^{\prime}\right)$-VIa may be transposable [28] or associated with plasmids that are selftransmissible among some Acinetobacter strains, or both $[27,28]$. Preliminary experiments indicate that many of the Bilbao isolates carry diverse collections of plasmids of various molecular sizes (unpublished results).

It was concluded that although class 1 integrons appear to be widely disseminated amongst clinical isolates of A. baumannii from the Bilbao region of Spain, these structures are not playing a major role in the dissemination of antibiotic resistance genes. Clinical isolates of $A$. baumannii from diverse worldwide locations seem to share resistance mechanisms with other genera, although many resistance plasmids from other genera are unstable in $A$. baumannii. Thus, despite their limited role at present, the presence of integrons in $84 \%$ of the clinical isolates examined in Bilbao is a cause for concern, as these structures may enhance the ability of these organisms to respond rapidly to the challenge of new antibiotics, enabling otherwise unstable resistance genes to be incorporated easily into the bacterial chromosome or into indigenous Acinetobacter plasmids. Isolates of $A$. baumannii from some centres are already extremely difficult to combat therapeutically [1], and the widespread occurrence of integrons in this species can only add to the problem.
L.G. is indebted to the Basque Government and the British Council for financial support, and to M.J. Canduela and F. López-Otsoa for their technical assistance.

\section{References}

1. Bergogne-Bérézin E, Towner KJ. Acinetobacter spp. as nosocomial pathogens: microbiological, clinical, and epidemiological features. Clin Microbiol Rev 1996; 9: 148-165.

2. Bergogne-Bérézin E. Resistance of Acinetobacter spp. to antimicrobials - overview of clinical resistance patterns and therapeutic problems. In: Bergogne-Bérézin E, Joly-Guillou ML, Towner KJ (eds) Acinetobacter - microbiology, epidemiology, infections, management. Boca Raton, CRC Press. 1996: 133-183.

3. Wolff M. Nosocomial infections caused by Acinetobacter spp. - therapeutic problems. In: Bergogne-Bérézin E, Joly-Guillou ML, Towner KJ (eds) Acinetobacter - microbiology, epidemiology, infections, management. Boca Raton, CRC Press. 1996: $225-236$.

4. Towner KJ. Plasmid and transposon behaviour in Acinetobacter. In: Towner KJ, Bergogne-Bérézin E, Fewson CA (eds) The biology of Acinetobacter. Taxonomy, clinical importance, molecular biology, physiology, industrial relevance. New York, Plenum. 1991: 149-167.

5. Young H-K, Gonzalez G, Zemelman R. Rearrangement of antibiotic resistance genes within a $\mathrm{Tn} 7$ integron structure in clinical Acinetobacter isolates. Abstracts of the 7th European Congress of Clinical Microbiology and Infectious Diseases 1995; abstract 228 .

6. Vila J, Navia M, Ruiz J, Casals C. Cloning and nucleotide sequence analysis of a gene encoding an OXA-derived $\beta$ lactamase in Acinetobacter baumannii. Antimicrob Agents Chemother 1997; 41: 2757-2759.

7. Gonzalez G, Sossa K, Bello H, Dominguez M, Mella S, Zemelman R. Presence of integrons in isolates of different biotypes of Acinetobacter baumannii from Chilean hospitals. FEMS Microbiol Lett 1998; 161: 125-128.

8. Seward RJ, Towner KJ. Detection of integrons in worldwide nosocomial isolates of Acinetobacter spp. Clin Microbiol Infect 1999; 5: 308-318.

9. Stokes HW, Hall RM. A novel family of potentially mobile DNA elements encoding site-specific gene-integration functions: integrons. Mol Microbiol 1989; 3: 1669-1683.

10. Hall RM, Recchia GD, Collis CM, Brown H, Stokes HW. Gene cassettes and integrons: moving antibiotic resistance genes in 
Gram-negative bacteria. In: Amábile-Cuevas CF (ed) Antibiotic resistance: from molecular basics to therapeutic options. Austin, Landes. 1996: 64-75.

11. Hall RM, Brookes DE, Stokes HW. Site-specific insertion of genes into integrons: role of the 59-base element and determination of the recombination cross-over point. $\mathrm{Mol}$ Microbiol 1991; 5: 1941-1959.

12. Collis CM, Hall RM. Gene cassettes from the insert region of integrons are excised as covalently closed circles. $\mathrm{Mol}$ Microbiol 1992; 6: 2875-2885.

13. Hall RM. Mobile gene cassettes and integrons: moving antibiotic resistance genes in Gram-negative bacteria. In: Chadwick DJ, Goode J (eds) Antibiotic resistance: origins, evolution, selection and spread (Ciba Foundation Symposium 207). Chichester, John Wiley \& Sons. 1997: 192-202.

14. Sallen B, Rajoharison A, Desvarenne S, Mabilat C. Molecular epidemiology of integron-associated antibiotic resistance genes in clinical isolates of Enterobacteriaceae. Microb Drug Resist 1995; 1: 195-202.

15. Martinez-Freijo P, Fluit AC, Schmitz F-J, Grek VSC, Verhoef $\mathrm{J}$, Jones ME. Class I integrons in Gram-negative isolates from different European hospitals and association with decreased susceptibility to multiple antibiotic compounds. J Antimicrob Chemother 1998; 42: 689-696.

16. Vila J, Ruiz J, Navia M et al. Spread of amikacin resistance in Acinetobacter baumannii strains isolated in Spain due to an epidemic strain. J Clin Microbiol 1999; 37: 758-761.

17. Ehrenstein B, Bernards AT, Dijkshoorn L et al. Acinetobacter species identification by using tRNA spacer fingerprinting. $J$ Clin Microbiol 1996; 34: 2414-2420.

18. National Committee for Clinical Laboratory Standards. Methods for dilution antimicrobial susceptibility tests for bacteria that grow aerobically, 2nd edn. Approved standard M7-A2. Villanova, National Committee for Clinical Laboratory Standards. 1990.

19. Webster CA, Towner KJ, Saunders GL, Crewe-Brown HH, Humphreys H. Molecular and antibiogram relationships of
Acinetobacter isolates from two contrasting hospitals in the United Kingdom and South Africa. Eur J Clin Microbiol Infect Dis 1999; 18: 595-598.

20. Seward RJ, Lambert T, Towner KJ. Molecular epidemiology of aminoglycoside resistance in Acinetobacter spp. $J$ Med Microbiol 1998; 47: 455-462.

21. Grundmann HJ, Towner KJ, Dijkshoorn L et al. Multicenter study using standardized protocols and reagents for evaluation of reproducibility of PCR-based fingerprinting of Acinetobacter spp. J Clin Microbiol 1997; 35: 3071-3077.

22. Webster CA, Towner KJ, Humphreys H, Ehrenstein B, Hartung $\mathrm{D}$, Grundmann $\mathrm{H}$. Comparison of rapid automated laser fluorescence analysis of DNA fingerprints with four other computer-assisted approaches for studying relationships between Acinetobacter baumannii isolates. $J$ Med Microbiol 1996; 44: 185-194.

23. Recchia GD, Hall RM. Gene cassettes: a new class of mobile element. Microbiology 1995; 141: 3015-3027.

24. Recchia GD, Hall RM. Plasmid evolution by acquisition of mobile gene cassettes: plasmid IE723 contains the aadB gene cassette precisely inserted at a secondary site in the IncQ plasmid RSF1010. Mol Microbiol 1995; 15: 179-187.

25. Miller GH, Sabatelli FJ, Naples L, Hare RS, Shaw KJ. The most frequently occurring aminoglycoside resistance mechanisms - combined results of surveys in eight regions of the world. $J$ Chemother 1995; 7 Suppl 2: 17-30.

26. Ploy M-C, Giamarellou H, Bourlioux P, Courvalin P, Lambert T. Detection of aac $\left(6^{\prime}\right)-I$ genes in amikacin-resistant Acinetobacter spp. by PCR. Antimicrob Agents Chemother 1994; 38: 2925-2928.

27. Lambert T, Gerbaud G, Courvalin P. Transferable amikacin resistance in Acinetobacter spp. due to a new type of $3^{\prime}$ aminoglycoside phosphotransferase. Antimicrob Agents Chemother 1988; 32: 15-19.

28. Lambert T, Gerbaud G, Bouvet P, Vieu J-F, Courvalin P. Dissemination of amikacin resistance gene aphA6 in Acinetobacter spp. Antimicrob Agents Chemother 1990; 34: 1244-1248. 